\title{
Stroke due to Percheron Artery Occlusion: Description of a Consecutive Case Series from Southern Portugal
}

\author{
Miguel Macedo ${ }^{1,2}$ \\ Diana Reis \\ Giovanni Cerullo ${ }^{1}$ \\ Leonor Aleluia ${ }^{1}$ José Drago ${ }^{1}$ Hipólito Nzwalo ${ }^{1,3}$ [1]
${ }^{1}$ Department of Internal Medicine, Stroke Unit, University Hospital Center of Algarve, Faro, Portugal
2 Department of Physical Medicine and Rehabilitation, University Hospital Center of Algarve, Faro, Portugal
${ }^{3}$ Department of Biomedical Sciences and Medicine, University of the Algarve, Faro, Portugal

J Neurosci Rural Pract 2022;13:151-154.

\author{
André Florêncio ${ }^{1}$ Catarina Frias ${ }^{1}$
}

Ana P. Fidalgo ${ }^{1}$

\begin{abstract}
Keywords

- bithalamic infarct

- the artery of Percheron

- ischemic stroke

- paramedian thalamic infarct

The artery of Percheron (AOP) is an abnormal variant of the arterial supply of the thalamus. Stroke caused by AOP occlusion is seldom reported. AOP leads to bilateral thalamic and rostral midbrain infarct presenting with unspecific manifestations. There are few descriptions of case series of stroke caused by AOP. We sought to review the clinicoradiological characteristics of AOP infarction from Algarve, Southern Portugal. Eight consecutive cases were retrospectively identified by searching the electronic clinical charts, as well as the stroke Unit database (2015-2020). Sociodemographic (age and gender) and clinicoradiological characteristics (etiological classification, admission severity, manifestations, and short- and long-term prognoses) were retrieved. The corresponding frequency of AOP infarction was $0.17 \%$ (95\% confidence interval: $0.05-0.28$ ). The mean age was 67.1 (range: $60-80$ ) years. The range of stroke severity evaluated assessed by the National Institute of Health Stroke Scale ranged from 5 to 23 (median=7.5). None of the patients receive acute ischemic stroke reperfusion treatment. AOP patterns were isolated bilateral paramedian thalamic $(n=2)$, bilateral paramedian and anterior thalamic $(n=2)$, and bilateral paramedian thalamic with rostral midbrain $(n=4)$. Two patients $(20 \%)$ died on the short term (30 days). At hospital discharge, six patients had functional disability of $\leq 2$ on the modified Rankin scale. In the follow-up at 6 months, half $(n=3)$ of the survivors had persistent hypersomnia and two had vascular dementia. Stroke from AOP presents with variable clinical and radiological presentations and patients do not receive alteplase. The shortterm survivor and the long-term functional independency can be compromised after AOS infarct.
\end{abstract}

\begin{abstract}
Address for correspondence Hipólito Nzwalo, MD, MSc, PhD, Department of Biomedical Sciences and Medicine, University of the Algarve, Estr. da Penha, 8005-139 Faro, Portugal (e-mail: nzwalo@gmail.com).
\end{abstract}

published online January 5, 2022
DOI https://doi.org/ 10.1055/s-0041-1741485. ISSN 0976-3147. (c) 2022. Association for Helping Neurosurgical Sick People. All rights reserved.

This is an open access article published by Thieme under the terms of the Creative Commons Attribution-NonDerivative-NonCommercial-License, permitting copying and reproduction so long as the original work is given appropriate credit. Contents may not be used for commercial purposes, or adapted, remixed, transformed or built upon. (https://creativecommons.org/ licenses/by-nc-nd/4.0/)

Thieme Medical and Scientific Publishers Pvt. Ltd., A-12, 2nd Floor, Sector 2, Noida-201301 UP, India 


\section{Introduction}

The artery of Percheron (AOP) is an uncommon variant of the thalamoperforating arteries characterized by a single dominant perforating artery originating in the proximal segment of the posterior cerebral artery (PCA) and supplying bilateral paramedian thalamus and rostral midbrain. ${ }^{1}$ Because of the thalamus complex functional anatomy, occlusion of the AOP causes variable and unspecific clinical manifestations. ${ }^{2}$ Most of knowledge about the characteristics and outcomes of stroke secondary to AOP comes from single case reports poses problems of publication bias. In addition, the number of consecutive case series of stroke as a result of AOP infarction in literature is sparse, reflecting the rarity of the syndrome and complicating appropriate prognostication in routine practice. Therefore, we sought to review the clinicoradiological characteristics of AOP infarction from stroke patients consecutively admitted to a single community representative center from Algarve, the southernmost region of Portugal.

\section{Methods}

Among the 4,705 consecutive acute ischemic stroke (AIS) cases (January 2015-November 2020), eight cases were retrospectively identified by searching the electronic clinical charts, as well as the Stroke Unit database from January 2015 to November 2020. Patients with documented first ever bilateral simultaneous ischemic lesions affecting the medial thalamus on brain magnetic resonance imaging (MRI) or cranial tomography were included. The individual electronic charts were reviewed to extract the sociodemographic (age and gender) and clinicoradiological (etiological classification, admission severity and manifestations, and short-term and long-term prognoses) characteristics. The Trial of Org 10172 in Acute Stroke Treatment (TOAST) was used for etiological classification. ${ }^{3}$ Radiological patterns of AOP infarction were classified as follows: bilateral paramedian thalamic with midbrain, bilateral paramedian thalamic without midbrain, bilateral paramedian thalamic with anterior thalamus and midbrain, and bilateral paramedian thalamic with anterior thalamus without midbrain. ${ }^{1}$ This study was approved by institutional ethics committee. Informed consent was waved due to its retrospective nature.

\section{Results}

All eight cases were confirmed with magnetic resonance. The corresponding frequency of AOP infarction was 0.17\% (95\% confidence interval: 0.05-0.28). - Table 1 resumes the sociodemographic and clinicoradiological characteristics. The mean age was 67.1 (range: 60-80) years and gender ratio was $1: 1$. Patients presented with varying levels of mental status disturbance, cognitive manifestations, and oculomotor nerve palsies. The range of stroke severity evaluated assessed by the National Institute of Health Stroke Scale (NIHSS) ranged from 5 to 23 (median $=7.5$ ). None of the patients receive AIS reperfusion treatment. Three of the four stroke patterns associated with AOP occurred: isolated bilateral paramedian thalamic $(n=2)$, bilateral paramedian and anterior thalamic $(n=2)$, and bilateral paramedian thalamic with rostral midbrain $(n=4)$. Representative cases are illustrated in - Fig. 1. Two patients (20\%) died on short term (30 days). At hospital discharge, six patients had functional

Table 1 Sociodemographic and clinicoradiological characteristics of eight consecutive cases of acute stroke due to the artery of Percheron occlusion from southern Portugal

\begin{tabular}{|c|c|c|c|c|c|c|c|c|}
\hline Case & Age (y) & Gender & $\begin{array}{l}\text { Clinical } \\
\text { manifestations }\end{array}$ & $\begin{array}{l}\text { Admission } \\
\text { NIHSS }\end{array}$ & Etiologic (TOAST) & $\begin{array}{l}\text { Radiological } \\
\text { pattern }\end{array}$ & $\begin{array}{l}\text { Discharge } \\
\text { functional } \\
\text { status } \\
(\mathrm{mRS} \leq 2) \\
\end{array}$ & $\begin{array}{l}\text { Long-term } \\
\text { functional } \\
\text { status }\end{array}$ \\
\hline 1 & 61 & $\mathrm{~F}$ & MSD & 3 & Cardioembolic & B & Yes & Hypersomnia \\
\hline 2 & 66 & $\mathrm{~F}$ & $\mathrm{BAI}$ & 4 & Cardioembolic & $A$ & Yes & $\mathrm{mRS} \leq 2$ \\
\hline 3 & 78 & $\mathrm{~F}$ & OMD & 5 & Cardioembolic & $\mathrm{C}$ & Yes & $\mathrm{mRS} \leq 2$ \\
\hline 4 & 60 & $\mathrm{M}$ & BAI, OMD & 16 & Undetermined & A & Yes & $\begin{array}{l}\text { Hypersomnia, } \\
\text { vascular } \\
\text { dementia }\end{array}$ \\
\hline 5 & 68 & $\mathrm{M}$ & MSD, BAI, OMD & 23 & Undetermined & C & $\begin{array}{l}\text { No } \\
\text { (deceased) }\end{array}$ & Not applicable \\
\hline 6 & 80 & $\mathrm{~F}$ & MSD, BAI & 24 & $\begin{array}{l}\text { Large-artery } \\
\text { atherosclerosis }\end{array}$ & B & $\begin{array}{l}\text { No } \\
\text { (deceased) }\end{array}$ & Not applicable \\
\hline 7 & 53 & $\mathrm{M}$ & BAI, MSD & 3 & Undetermined & B & Yes & $\begin{array}{l}\text { Hypersomnia, } \\
\text { vascular } \\
\text { dementia }\end{array}$ \\
\hline 8 & 71 & $\mathrm{M}$ & OMD & 5 & Undetermined & B & Yes & $\mathrm{mRS} \leq 2$ \\
\hline
\end{tabular}

Abbreviations: BAI, behavioral/amnesic impairment; F, female; M, male; mRS, the modified Rankin score; MSD, mental status disturbance; NIHSS, National Institute of Health Stroke Scale; OMD, ocular movement disorders; TOAST: Trial of Org 10172 in acute stroke treatment. 


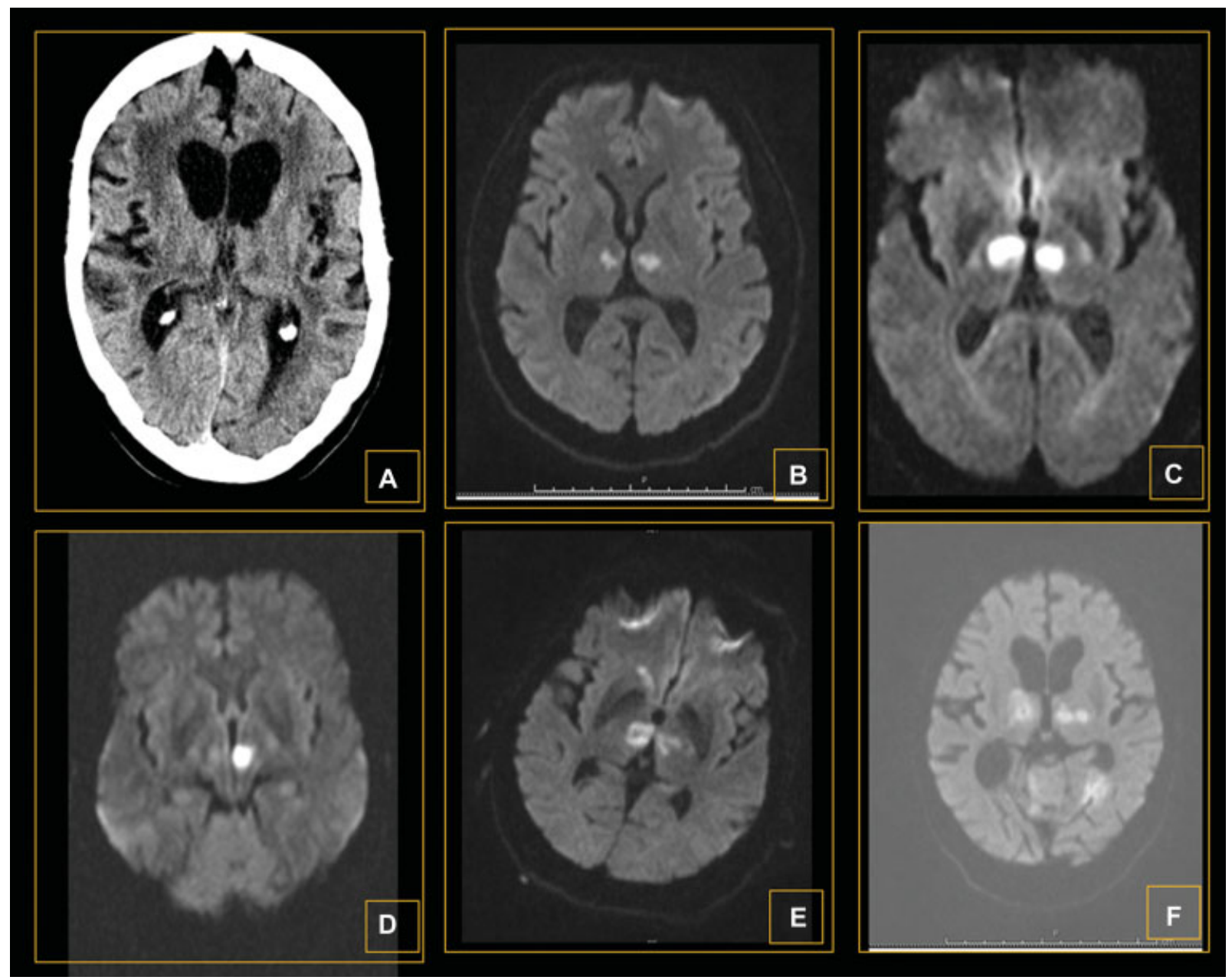

Fig. 1 Representative radiologic appearance of the artery of Percheron infarction, bilateral paramedian lesions (A) hypodense on brain cranial tomography and (B) restriction on magnetic resonance (MR) diffusion-weighted imaging (DWI); combined bilateral thalamic lesion (C) with rostral mesencephalic on DWI MR ; combined anterior (D) with paramedian bilateral lesions on DWI MR.

disability of $\leq 2$ on the modified Rankin scale (mRS). In the follow-up, at 6 months, half $(n=3)$ of the survivors had persistent hypersomnia and two had vascular dementia.

\section{Discussion}

The frequency of AOP in our study (0.17\%) are consistent with findings from the few available representative case series of AOP infarcts which have shown a frequency of 0.1 to $0.6 \% .^{2,4-7}$ In the absence of the classic signs of stroke, the presentation with behavior manifestations, somnolence may suggest alternative diagnosis such as inflammation, infection, metabolic, infiltrative tumor, or deep cerebral vein thrombosis. In fact, patients with AOS infarcts rarely receive thrombolysis because of delayed AIS recognition. ${ }^{7-9}$ None of our patients received acute reperfusion for AIS because the diagnosis was not promptly considered by the relatives or by the emergency physicians. With significant variation and overlap, the thalamus has four vascular territories: anterior, paramedian, inferolateral, and posterior. The paramedian or thalamoperforating arteries, which arise from the proximal segment of the PCA, ${ }^{1}$ supply the paramedian thalamus. The lesion patterns of AOP reflect the known variations of territorial contribution of the paramedian arteries. ${ }^{1}$ Indeed, in our case series, the bilateral paramedian thalamic with anterior thalamus and midbrain involvement subtype, which is associated with the most dominant paramedian artery variant, did not occur. ${ }^{4}$ As shown in our case series, both short-term survivor and the long-term functional independency can be compromised after AOS infarct. Thus, highly clinical and radiological suspicion is important to improve the chances of prompt treatment and favorable outcomes. ${ }^{10}$ There are important limitations worthwhile pointing out. The study was retrospective and the sample size small as in the available studies. The possibility of missing more dramatic cases with very rapid unfavorable outcomes or minor cases, with very mild symptoms cannot be ruled out. However, AOS infarct is rare and our incidence rate was within the figures from the literature. The largest case series presented so far included 37 patients from two different hospitals. ${ }^{1}$ On the other hand, given the fact of our Stoke Unit being the sole one serving the region, ${ }^{11}$ we do believe that study findings are representative of that from the community. 


\section{Conclusion}

In conclusion, our case series confirms that stroke due to AOP is a rare event, with clinical and radiological variability, including an initial severity. The evolution to death is a possibility in the acute phase which is explained by lesion of strategic structures involved in maintaining wakefulness. Regardless of motor autonomy at discharge, longterm functional impairments, namely, persistent hypersomnia and dementia, do occur in a high proportion of survivors.

\section{Funding}

None.

\section{Conflict of Interest \\ None declared.}

\section{References}

1 Lazzaro NA, Wright B, Castillo M, et al. Artery of percheron infarction: imaging patterns and clinical spectrum. AJNR Am J Neuroradiol 2010;31(07):1283-1289

2 Carrera E, Michel P, Bogousslavsky J. Anteromedian, central, and posterolateral infarcts of the thalamus: three variant types. Stroke 2004;35(12):2826-2831
3 Adams HP Jr., Bendixen BH, Kappelle LJ, et al. Classification of subtype of acute ischemic stroke. Definitions for use in a multicenter clinical trial. TOAST. Trial of Org 10172 in acute stroke treatment. Stroke 1993;24(01):35-41

4 Kumral E, Evyapan D, Balkir K, Kutluhan S. Bilateral thalamic infarction. Clinical, etiological and MRI correlates. Acta Neurol Scand 2001;103(01):35-42

5 Jiménez Caballero PE. Bilateral paramedian thalamic artery infarcts: report of 10 cases. J Stroke Cerebrovasc Dis 2010;19 (04):283-289

6 Amin OSM, Shwani SS, Zangana HM, Hussein EM, Ameen NA, Ameen NA. Bilateral infarction of paramedian thalami: a report of two cases of artery of Percheron occlusion and review of the literature. BMJ Case Rep 2011;2011:2-8

7 Xu Z, Sun L, Duan Y, Zhang J, Zhang M, Cai X. Assessment of Percheron infarction in images and clinical findings. J Neurol Sci 2017;383:87-92

8 Mogildea M, Varela M, Martins C, Joaquim N, Soleiro J, Nzwalo H. Irreversible hypersomnolence after bilateral thalamic infarction. J Neurosci Rural Pract 2018;9(01):167-168

9 Stamm BJ, Lineback CM, Skolarus LE, Morgenstern LB, Shah GV. Artery of percheron infarct: 12 cases and their complex clinical courses. Neurohospitalist 2018;8(03):141-145

10 Agarwal S, Chancellor B, Howard J. Clinical-radiographic correlates of Artery of Percheron infarcts in a case series of 6 patients. J Clin Neurosci 2019;61:266-268

11 Nzwalo H, Nogueira J, Félix C, et al. Incidence and case-fatality from spontaneous intracerebral hemorrhage in a southern region of Portugal. J Neurol Sci 2017;380:74-78 